\title{
Smoking and hepatocellular carcinoma mortality
}

\author{
ABBY B. SIEGEL ${ }^{1 *}$, KRISTINA CONNER ${ }^{1 *}$, SHUANG WANG ${ }^{2}$, JUDITH S. JACOBSON ${ }^{2}$, \\ DAWN L. HERSHMAN ${ }^{1}$, ROSA HIDALGO ${ }^{1}$, ELIZABETH C. VERNA ${ }^{1}$, KARIM HALAZUN ${ }^{3}$, \\ WILLIAM BRUBAKER ${ }^{3}$, JONAH ZARETSKY ${ }^{3}$, ANNA MONIODIS ${ }^{1}$, LISSETTE DELGADO-CRUZATA ${ }^{2}$, \\ LORNA DOVE $^{1}$, JEAN EMOND $^{3}$, TOMOAKI KATO ${ }^{3}$, ROBERT S. BROWN Jr ${ }^{1}$ and ALFRED I. NEUGUT ${ }^{1}$ \\ ${ }^{1}$ Department of Medicine; ${ }^{2}$ Mailman School of Public Health; ${ }^{3}$ Department of Surgery, \\ Columbia University, New York, NY 10032, USA
}

Received July 5, 2011; Accepted August 8, 2011

DOI: $10.3892 / \mathrm{etm} .2011 .351$

\begin{abstract}
The association between cigarette smoking and mortality from hepatocellular carcinoma (HCC) is ambiguous. We analyzed the association between smoking and mortality in HCC patients seen at our center. We collected data retrospectively on patients diagnosed with HCC between 2002 and 2009. We estimated the association of smoking history with demographic, clinical and treatment factors. We then modeled these factors as predictors of mortality. Among smokers, we analyzed the effects of pack-year history and cessation times on survival. Two hundred and twenty-three out of 444 patients with HCC had a history of smoking. Smokers were more likely to be younger at diagnosis, to have $\alpha$ fetoprotein (AFP) values less than the median, and to have had surgery $(\mathrm{p}=0.04)$ compared to non-smokers. In a Cox model, younger age, lower AFP and Child's Class were all independently predictive of survival, but smoking was not. Smokers with over 20 packyears did not have worse survival than lighter smokers, and cessation times also did not affect survival after controlling for age. We found a significant interaction between smoking and drinking. In our data, smoking was not independently associated with HCC survival in a multivariable model. Smoking was associated with favorable prognostic features which likely outweighed any independent effect of smoking.
\end{abstract}

\section{Introduction}

Hepatocellular carcinoma (HCC) has the most rapidly rising cancer mortality rate in the US. Its known risk factors include hepatitis B and C, alcoholic cirrhosis and non-alcoholic steato-

Correspondence to: Dr Abby B. Siegel, Department of Medicine, Columbia University, 622 West 168th Street, PH-14, New York, NY 10032, USA

E-mail: aas54@columbia.edu

${ }^{*}$ Contributed equally

Key words: smoking, hepatocellular carcinoma, mortality hepatitis, or NASH. Smoking is related to cancer incidence and mortality in many malignancies, including carcinomas of the lung, stomach, esophagus, bladder, pancreas, kidney and colon (1,2). Cigarette smoking has been investigated as an independent predictor of mortality in patients with $\mathrm{HCC}$, but its effects have not been well documented (3-5). Smoking creates toxic metabolites that theoretically could increase cancer aggressiveness (6). Since alcohol intake is strongly associated with HCC, and the use of tobacco is strongly associated with alcohol intake in many populations, the role of tobacco as an independent causal agent in HCC mortality has been difficult to evaluate (7). A large cohort study in China examined the correlation between mortality from HCC and alcohol use, cigarette smoking and dietary habits and found an association between smoking and HCC mortality only among females (8). A large cohort study in Japan found that smoking was related to an increased risk of mortality from HCC in a dose-response fashion; those who smoked more had higher HCC mortality rates. However, this study reported results only for univariate analyses and did not assess possible confounders or synergistic effects (3). An analysis of data from the British Whitehall cohort study of 17,363 male government employees followed for up to 38 years suggested an increased risk of liver cancer mortality among men who were current smokers at baseline, but only 57 subjects died of liver cancer during follow-up, and the association was not statistically significant (5). In a retrospective study of $262 \mathrm{HCC}$ patients in Hawaii, Wong et al found that HCC survival was associated with alcohol consumption and with hepatitis B, but not with smoking (9). However, these authors did not evaluate the interaction between alcohol use and smoking or measure smoking intensity or duration.

Current smokers have a higher risk for mortality from many diseases than non-smokers and past smokers, but the difference between current and past smokers' risks may be related to the time interval since smoking cessation. For instance, a study of lung cancer incidence found that quitters had the same risk as current smokers for the first 3 years, but that individuals who had stopped smoking more than 20 years ago had the same risk of lung cancer as never-smokers (10). In this study, we report a retrospective study of the association of smoking with mortality among patients diagnosed with HCC at our large referral center in New York City. 


\section{Materials and methods}

We identified all patients who were diagnosed either pathologically or clinically with HCC between January 1, 2002, and February 7, 2009, at the Columbia University Medical Center (CUMC), a tertiary referral hospital for liver disease and transplantation located in Washington Heights, a predominantly Hispanic neighborhood in New York City. Using the ICD-9 code 155.0 (malignant neoplasm liver, primary) as a search criterion in CUMC's clinical information system, we first identified all patients diagnosed with HCC. We then searched for patients with an $\alpha$ fetoprotein (AFP) $>200 \mathrm{ng} / \mathrm{ml}$. We clinically confirmed all these patients to have HCC through a review of imaging and clinical characteristics using AASLD criteria (11). We also evaluated a separate pathology database that tracks all pathologically diagnosed HCC at our institution to confirm inclusion of pathologically eligible cases. Our protocol was approved by the Institutional Review Board of Columbia University Medical Center.

Using paper charts and Columbia's electronic data warehouse, we abstracted age at diagnosis, gender, race/ethnicity (self-reported), AFP, risk factors for liver disease, Child-Pugh score and history of self-reported alcohol use and smoking. All patients age $\geq 18$ years were included in the sample. Smoking history data were collected as ever/never smoked and, among ever smokers, time since the most recent cessation, average packs per day and smoking duration in years. Cessation time was computed from data in patients' charts as the interval from the quit date to the date of HCC diagnosis. Patients who reported that they had quit after their date of diagnosis were considered current smokers in the analysis. Child-Pugh score was computed using serum total bilirubin, albumin, INR, ascites and encephalopathy grade at diagnosis, or closest to and preceding the date of surgery for those who underwent surgery. Patients were categorized as significant alcohol users if they reported having had an average of more than two drinks per day for at least 1 year. Patients were followed until death or July 2009.

Demographic and clinical characteristics of smokers and non-smokers (race/ethnicity, gender, median AFP values, stage, patient age, significant alcohol use, Child-Pugh score, HCC grade and presence of microvascular invasion for patients with available pathology samples) were compared; the statistical significance of differences in proportions was evaluated by means of Chi-square and Fisher's exact tests. We developed logistic regression models to analyze the association of smoking status with the above variables, Kaplan-Meier curves with log-rank tests to estimate the association of smoking behavior with survival and Cox proportional hazards models to evaluate the association of smoking with mortality, with potential confounders taken into account. We specifically modeled the interaction between smoking and alcohol in the Cox model. All statistical analyses were performed using SAS software (version 9.1; Cary, NC, USA).

\section{Results}

Of 444 patients diagnosed with HCC between 1992 and 2007 in our sample, the 223 who were ever smokers differed from the 221 never-smokers in demographic and clinical character-

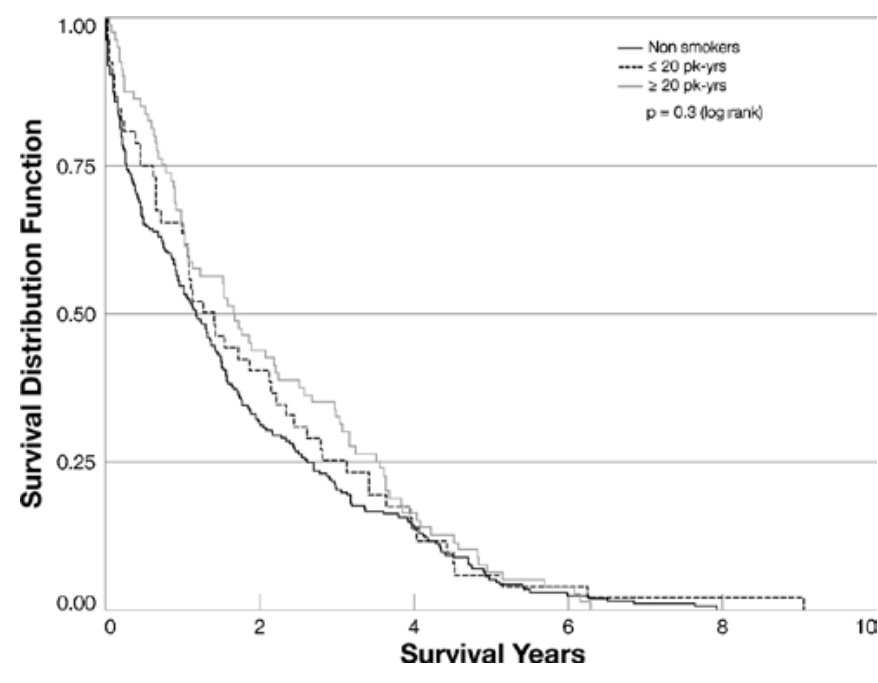

Figure 1. Kaplan-Meier curves for never smokers, light smokers $(<20$ packyears) and heavy smokers (>20 pack-years).

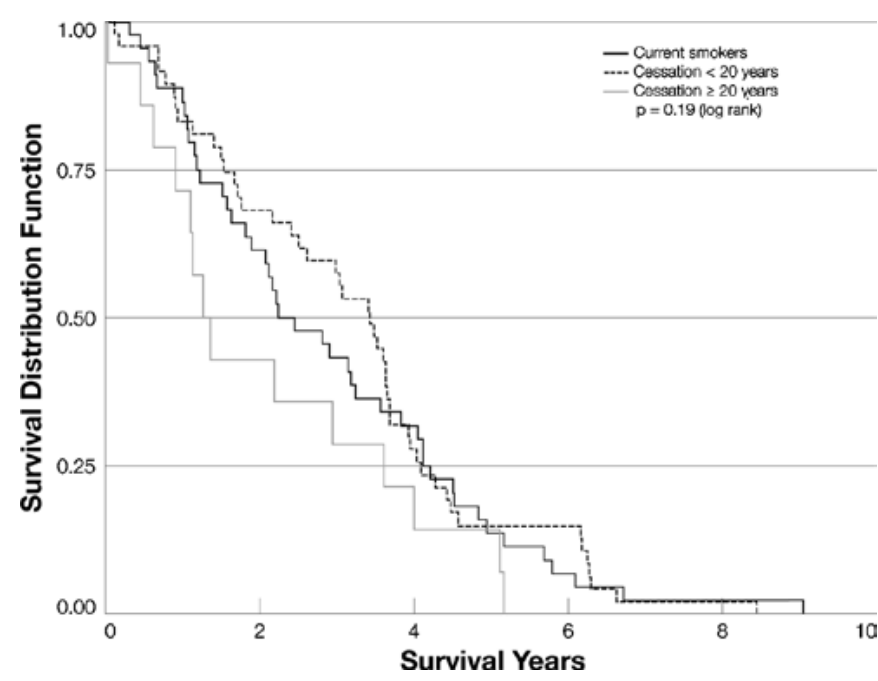

Figure 2. Kaplan-Meier curves for current smokers, cessation times $<20$ years and cessation times $\geq 20$ years.

istics (Table I). Smokers were more likely to be Caucasian and less likely to be Asian, more likely to be male and more likely to be $<60$ years of age. Smokers were also more likely than non-smokers to drink, to have AFP levels below the median, to be male and to have had surgery (either resection or liver transplantation). Median survival was 16.3 months among smokers and 14.5 months among non-smokers ( $\mathrm{p}=0.1$; log-rank).

Fig. 1 shows Kaplan-Meier curves for never smokers, light smokers ( $<20$ pack-years) and heavy smokers ( $\geq 20$ pack-years). The three groups did not differ significantly with respect to survival. Current smokers, patients who had quit within the past 20 years and patients who had quit $>20$ years ago also did not differ in terms of overall survival (Fig. 2). In a Cox proportional hazards model that included smoking, alcohol use, age at diagnosis, gender, median AFP, Child-Pugh score, receipt of surgery and significant drinking history, receipt of surgery was the most significant factor associated with decreased mortality [mortality hazard ratio $(\mathrm{HR})=0.30 ; 95 \%$ CI $0.23-0.40$; $\mathrm{p}<0.0001]$. Smoking was not associated with mortality in 
Table I. Characteristics of smokers and non-smokers.

\begin{tabular}{|c|c|c|c|c|c|c|c|}
\hline & \multicolumn{2}{|c|}{ Ever smokers } & \multicolumn{2}{|c|}{ Never smokers } & \multicolumn{2}{|c|}{ Total } & \multirow{2}{*}{$\frac{\text { Chi-square }}{\text { p-value }}$} \\
\hline & $\mathrm{N}$ & $\%$ & $\mathrm{~N}$ & $\%$ & $\mathrm{~N}$ & $\%$ & \\
\hline Total & 223 & 100.0 & 221 & 100.0 & 444 & 100.0 & 0.0200 \\
\hline \multicolumn{8}{|l|}{ Age } \\
\hline$\geq 60$ & 94 & 42.2 & 116 & 52.5 & 210 & 47.3 & \\
\hline$<60$ & 129 & 57.8 & 101 & 45.7 & 230 & 51.8 & \\
\hline Missing & & & 4 & 1.8 & 4 & 0.9 & \\
\hline Gender & & & & & & & $<0.0001$ \\
\hline Male & 198 & 88.8 & 146 & 66.1 & 344 & 77.5 & \\
\hline Female & 25 & 11.2 & 74 & 33.5 & 99 & 22.3 & \\
\hline Missing & & & 1 & 0.5 & 1 & 0.2 & \\
\hline \multicolumn{7}{|l|}{ Race/ethnicity } & 0.0100 \\
\hline White & 106 & 47.5 & 77 & 34.8 & 183 & 41.2 & \\
\hline Black & 29 & 13.0 & 29 & 13.1 & 58 & 13.1 & \\
\hline Hispanic & 67 & 30.0 & 75 & 33.9 & 142 & 32.0 & \\
\hline Asian & 11 & 4.9 & 29 & 13.1 & 40 & 9.0 & \\
\hline Missing & 10 & 4.5 & 11 & 5.0 & 21 & 4.7 & \\
\hline \multicolumn{7}{|l|}{ Child-Pugh score } & 0.9000 \\
\hline$A(5,6)$ & 88 & 39.5 & 89 & 40.3 & 177 & 39.9 & \\
\hline B (7-9) & 63 & 28.3 & 62 & 28.1 & 125 & 28.2 & \\
\hline$C(10-15)$ & 70 & 31.4 & 65 & 29.4 & 135 & 30.4 & \\
\hline Missing & 2 & 0.9 & 5 & 2.3 & 7 & 1.6 & \\
\hline \multicolumn{7}{|l|}{ Stage } & 0.0600 \\
\hline 1 & 66 & 29.6 & 50 & 22.6 & 116 & 26.1 & \\
\hline 2 & 64 & 28.7 & 51 & 23.1 & 115 & 25.9 & \\
\hline $3-5$ & 80 & 35.9 & 100 & 45.2 & 180 & 40.5 & \\
\hline Missing & 13 & 5.8 & 20 & 9.0 & 33 & 7.4 & \\
\hline \multicolumn{7}{|l|}{ Treatment } & 0.0400 \\
\hline Surgery & 122 & 54.7 & 99 & 44.8 & 221 & 49.8 & \\
\hline No surgery & 101 & 45.3 & 121 & 54.8 & 222 & 50.0 & \\
\hline Missing & & 0.0 & 1 & 0.5 & 1 & 0.2 & \\
\hline \multicolumn{7}{|l|}{ AFP max (ng/ml) } & 0.0200 \\
\hline$\geq 28$ & 87 & 39.0 & 110 & 49.8 & 197 & 44.4 & \\
\hline$<28$ & 121 & 54.3 & 98 & 44.3 & 219 & 49.3 & \\
\hline Missing & 15 & 6.7 & 13 & 5.9 & 28 & 6.3 & \\
\hline \multicolumn{7}{|l|}{$\mathrm{HCV}$} & 0.0010 \\
\hline$(+)$ & 166 & 74.4 & 118 & 53.4 & 284 & 64.0 & \\
\hline$(-)$ & 57 & 25.6 & 103 & 46.6 & 160 & 36.0 & \\
\hline \multicolumn{7}{|l|}{$\mathrm{HBV}$} & 0.0300 \\
\hline$(+)$ & 31 & 13.9 & 48 & 21.7 & 79 & 17.8 & \\
\hline$(-)$ & 192 & 86.1 & 171 & 77.4 & 363 & 81.8 & \\
\hline Missing & & 0.0 & 2 & 0.9 & 2 & 0.5 & \\
\hline \multicolumn{7}{|l|}{ ETOH } & 0.0030 \\
\hline$(+)$ & 73 & 32.7 & 44 & 19.9 & 117 & 26.4 & \\
\hline$(-)$ & 150 & 67.3 & 174 & 78.7 & 324 & 73.0 & \\
\hline Missing & & 0.0 & 3 & 1.4 & 3 & 0.7 & \\
\hline Total & 223 & 100.0 & & & & & \\
\hline \multicolumn{8}{|c|}{ Time since smoking cessation } \\
\hline N/A (current smoker) & 93 & 41.7 & & & & & \\
\hline 6 months to 20 years & 79 & 35.4 & & & & & \\
\hline$>20$ years & 26 & 11.7 & & & & & \\
\hline Missing & 25 & 11.2 & & & & & \\
\hline \multicolumn{8}{|l|}{ Pack-years } \\
\hline$<20$ & 52 & 23.3 & & & & & \\
\hline $20+$ & 118 & 52.9 & & & & & \\
\hline Unknown & 53 & 23.8 & & & & & \\
\hline
\end{tabular}


Table II. Cox proportional hazards model of overall survival.

\begin{tabular}{|c|c|c|c|}
\hline Risk factor & Hazard ratio & $95 \% \mathrm{CI}$ & p-value \\
\hline Age & & & 0.950 \\
\hline$<60$ & 1.00 & Referent & \\
\hline$\geq 60$ & 1.01 & $0.80-1.27$ & \\
\hline Gender & & & 0.680 \\
\hline Female & 1.00 & Referent & \\
\hline Male & 1.06 & $0.81-1.38$ & \\
\hline $\operatorname{AFP}(\mathrm{ng} / \mathrm{ml})$ & & & 0.600 \\
\hline$<28$ & 1.00 & Referent & \\
\hline$\geq 28$ & 1.07 & $0.83-1.39$ & \\
\hline \multicolumn{4}{|l|}{ Child-Pugh Score } \\
\hline A & 1.00 & Referent & \\
\hline B & 1.08 & $0.83-1.41$ & 0.560 \\
\hline $\mathrm{C}$ & 1.29 & $0.98-1.70$ & 0.070 \\
\hline Surgery & & & $<0.001$ \\
\hline None & 1.00 & Referent & \\
\hline Any & 0.30 & $0.23-0.40$ & \\
\hline Hepatitis C & & & 0.500 \\
\hline Yes & 1.00 & Referent & \\
\hline No & 1.10 & $0.69-1.20$ & \\
\hline Hepatitis B & & & 0.700 \\
\hline Yes & 1.00 & Referent & \\
\hline No & 1.08 & $0.66-1.31$ & \\
\hline \multicolumn{4}{|l|}{$\begin{array}{l}\text { Smoking drinking } \\
\text { joint effect }\end{array}$} \\
\hline $\begin{array}{l}\text { Non-smokers } \\
\text { who do not drink (-/-) }\end{array}$ & 1.00 & Referent & \\
\hline $\begin{array}{l}\text { Non-smokers } \\
\text { who drink }(-/+)\end{array}$ & 1.61 & $1.09-2.40$ & 0.020 \\
\hline $\begin{array}{l}\text { Smokers who (+/-) } \\
\text { do not drink }\end{array}$ & 1.02 & $0.80-1.32$ & 0.850 \\
\hline $\begin{array}{l}\text { Smokers who } \\
\text { drink (+/+) }\end{array}$ & 0.95 & $0.69-1.31$ & 0.760 \\
\hline
\end{tabular}

this model (Table II). When we evaluated those patients who received and did not receive surgery separately, we still found no difference in survival between those who smoked more heavily and those who were moderate smokers or non-smokers (data not shown). Similarly, we saw no significant association of time since cessation with survival (data not shown).

A Kaplan-Meier curve comparing patients who neither smoked nor drank, patients who only smoked, patients who only drank and patients who both smoked and drank yielded statistically significant differences in survival in a univariate analysis ( $\mathrm{p}=0.004$; Fig. 3). Non-smokers who used significant amounts of alcohol had the poorest survival at 4 years, whereas smokers who used significant alcohol had the best survival at 4 years. We then decided to study this interaction more closely and evaluated the relationship between smoking and drinking in our Cox model. We found a statistically significant interaction between the two ( $\mathrm{p}=0.02$; data not shown). Using non-smokers/non-significant drinkers (-/-) as our reference group, we found that non-smokers who drink (-/+) were significantly different, indicating an effect for signifi-

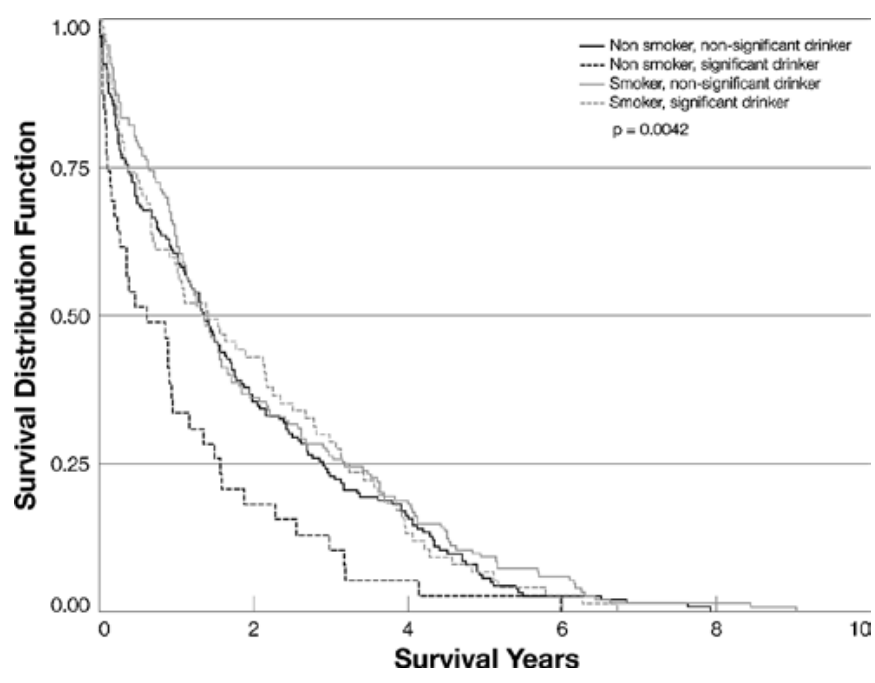

Figure 3. Kaplan-Meier survival curves for smokers, drinkers and combinations.

cant alcohol consumption on HCC mortality. When smokers who did not drink (+/-) were compared to non-smokers/nondrinkers, there was no difference in HCC mortality, a result that agrees with our previous finding that smoking has no effect on HCC mortality in this cohort. Notably, patients who were both smokers and significant drinkers $(+/+)$ did not have higher mortality than those who neither smoke nor drink (-/) (HR=0.95; CI 0.69-1.31; $p=0.76$; Table II), perhaps because of the difference in age and treatment between the two groups.

\section{Discussion}

In our sample of HCC patients, the strongest predictor of increased mortality was not receiving surgery. Smoking was not associated with overall mortality, but smokers were more likely than non-smokers to receive surgery $(\mathrm{p}=0.04)$. Receipt of surgery is typically a strong predictor of better outcome because those who receive surgery usually have more limited disease and a better performance status than those who do not. We found that the mortality was more than three times higher among non-transplanted patients compared to transplanted patients $(\mathrm{HR}=3.62)$, even when AFP and other factors were taken into account (12). In our present sample, smokers had lower AFP and were also younger than non-smokers. However, in our Cox models, we took receipt of surgery, younger age and lower AFP into account and still found no significant effect of smoking on mortality. Separate Kaplan-Meier comparisons among those who received and did not receive surgery also found that smokers and non-smokers did not differ in survival (data not shown).

Our analyses also did not support the hypotheses that heavier smokers would have poorer HCC survival than lighter smokers. Patients who stopped smoking less than 20 years before their diagnosis had better survival than patients who were still smoking at the time of diagnosis, but patients who had stopped smoking 20 or more years before their diagnosis had the poorest survival. These associations were not statistically significant and may reflect the 4-year age difference between those who stopped smoking 20 or more years ago and those who stopped more recently. 
We found a significant interaction between smoking and drinking, but our results are difficult to interpret. It is reasonable that non-smokers who drank would have a poorer survival than non-smokers who did not drink, but it is not clear why drinkers who smoked had lower mortality rates than drinkers who did not smoke. Among our subjects, drinkers were similar to non-drinkers in age (mean 59 vs. 60, respectively), but were less likely to receive surgery $(p=0.05)$. Perhaps the cause of $\mathrm{HCC}$ in non-drinking non-smokers resulted in more lethal disease or, more likely, that these patients had other unmeasured characteristics which affected their survival.

Our study had several limitations. First, patients who gave any smoking history were considered to be smokers, regardless of the amount and duration of their smoking. Patients with a very remote or insignificant smoking history were included in the smoking group this may have biased the observed association of smoking with mortality toward the null. In addition, 25 patients who reported any smoking had charts that were missing packyear data. The exclusion of those patients from the multivariable models may have led to bias if those patients differed in some way from those who were included. Similarly, our coding for drinking was relatively imprecise, and did not account for degree of alcohol use. We coded alcohol use as 'significant' not significant rather than any/none to try to evaluate those for whom alcohol use was a potential contributor to their HCC.

In conclusion, surgery was the dominant predictor of $\mathrm{HCC}$ mortality in our sample. As in previous studies, we found that smoking was not significantly associated with increased mortality in HCC in a multivariate model. Heavy smokers had the best unadjusted 4-year survival rates, whereas non-smokers had the poorest 4-year survival rates. Patients with the longest cessation times had the worst 4-year survival rates, but they were older than the other patients. Our study also showed that non-smokers have a number of characteristics associated with mortality, highlighting the importance of further research in understanding the causes of mortality in non-smoking HCC patients.

\section{References}

1. Peto R, Lopez AD, Boreham J, Thun M, Heath C Jr and Doll R: Mortality from smoking worldwide. Br Med Bull 52: 12-21, 1996.

2. Chao A, Thun MJ, Jacobs EJ, Henley SJ, Rodriguez C and Calle EE: Cigarette smoking and colorectal cancer mortality in the cancer prevention study II. J Natl Cancer Inst 92: 1888-1896, 2000.

3. Ogimoto I, Shibata A, Kurozawa Y, et al: Risk of death due to hepatocellular carcinoma among smokers and ex-smokers. Univariate analysis of JACC study data. Kurume Med J 51: 71-81, 2004.

4. Marrero JA, Fontana RJ, Fu S, Conjeevaram HS, Su GL and Lok AS: Alcohol, tobacco and obesity are synergistic risk factors for hepatocellular carcinoma. J Hepatol 42: 218-224, 2005.

5. Batty GD, Kivimaki M, Gray L, Smith GD, Marmot MG and Shipley MJ: Cigarette smoking and site-specific cancer mortality: testing uncertain associations using extended follow-up of the original Whitehall study. Ann Oncol 19: 996-1002, 2008.

6. Taioli E: Gene-environment interaction in tobacco-related cancers. Carcinogenesis 29: 1467-1474, 2008.

7. Yu MC and Yuan JM: Environmental factors and risk for hepatocellular carcinoma. Gastroenterology 127: S72-S78, 2004.

8. Evans AA, Chen G, Ross EA, Shen FM, Lin WY and London WT: Eight-year follow-up of the 90,000-person Haimen City cohort: I. Hepatocellular carcinoma mortality, risk factors, and gender differences. Cancer Epidemiol Biomarkers Prev 11: 369-376, 2002.

9. Wong LL, Limm WM, Tsai N and Severino R: Hepatitis B and alcohol affect survival of hepatocellular carcinoma patients. World J Gastroenterol 11: 3491-3497, 2005.

10. Ockene JK, Kuller LH, Svendsen KH and Meilahn E: The relationship of smoking cessation to coronary heart disease and lung cancer in the Multiple Risk Factor Intervention Trial (MRFIT). Am J Public Health 80: 954-958, 1990.

11. Bruix J and Sherman M: Management of hepatocellular carcinoma. Hepatology 42: 1208-1236, 2005.

12. Yu JC, Neugut AI, Wang S, et al: Racial and insurance disparities in the receipt of transplant among patients with hepatocellular carcinoma. Cancer 116: 1801-1809, 2010. 